and to demonstrate conditions under which neighbourhood care as an informal caring network can develop.

Social Work Services Group, Edinburgh

\title{
Sociology and Social Policy
}

John Bond

Walker, A., 'The social creation of poverty and dependency in old age', Journal of Social Policy, 9, i98o, pp. 49-75.

This series of abstracts begins with, perhaps, the most relevant article to appear in 1980 . With increasing unemployment, continuing inflation and a deepening recession the living standards of many old people remain below the state's poverty line - the supplementary benefit rate appropriate to each family. From his review of recent data Walker reports that 'one in four elderly people have incomes which are equal to or below the poverty line' (p. 5o).

The central purpose of this article is to explore 'the relationship between poverty in old age and social changes and social policies which have contributed to the social creation of dependency on the state' (p. 51). A large part of the article is taken up with an empirical examination of this relationship. A comprehensive review of secondary data on earnings, incomes and assets, housing circumstances and benefits in kind are presented to show the extent of poverty among old people and to help explain the causes of poverty in old age.

What are the causes of poverty in old age? Walker argues that it has been recognized for a long time that the elderly feature in the lower levels of the income distribution because they are usually not in work. Society rewards present work; it does not reward past work and therefore it does not reward old age. The elderly are discriminated against by economic and social policies which benefit the young and the well-off. He shows that poverty in old age is related to low resources and restricted access to resources throughout the life cycle.

This relationship is well illustrated by describing the process of retirement. Prior to retirement manual workers - the majority of elderly men experience reduced socio-economic status. Increasingly early retirement schemes are pushing elderly workers into less skilled jobs and into unemployment. After retirement the inequalities resulting from low pay, unemployment, disability and for women, sex discrimination, are carried through into old age. The decline in the real value of savings and pensions means that the worst off are the very old. 
In conclusion Walker argues that it is not 'chronological' age that is significant in causing poverty in old age but the relationship between the social construction of old age - retirement policies for example - and the social division of labour - incqualities in pension rights between manual and non-manual workers, for example. 'To eradicate poverty... is not simply a matter of providing old-age pensions but one of changing the relationship between age and the labour market..., and by implication, changing the socially divided relationship between work and rewards' (p. 73).

\section{COMMENT}

Articles of this kind which challenge the whole basis of current social policy are an abstractor's nightmare. In the first place this article is extremely dense and many arguments require far more space in order to provide a coherent presentation. (This abstract by implication is no better). This aside the article lacks a full discussion of the theoretical implications of the data presented. For example, Walker although writing off disengagement theory and other functionalist theories as self-fulfilling fails to provide a coherent alternative. I would have liked to have seen more space spent in discussing pitfalls of the theories, which form the basis of current social policies. Likewise I would have liked some alternative theories upon which to hang new social policies. Alas, I have sympathy with the author because such theories are embryonic in form.

Liang, J., Kahana, E. and Doherty, E., 'Financial well-being among the aged: a further elaboration', fournal of Gerontology, 35, I980, pp. 409-20.

This article provides a contrast to my first selection in that it seeks to test a specific theoretical model. It does, however, have more general relevance to our understanding of poverty in old age. Poverty is a relative concept ${ }^{1}$ and although the poverty line is an objective measure it is changed in relation to society's relative affluence. The importance of this article is that it highlights the problematic nature of the relationship between objective economic status and subjective financial wcll-being. The article considers two concepts relevant to this problem: relative deprivation ${ }^{2}$ and distributive justice. ${ }^{3}$

Although these two concepts are not particularly new we lack sensitive measurement techniques for them. This article describes a study which aims to refine measures of financial satisfaction and relative deprivation. 
It describes a model which incorporates both relative deprivation and distributive justice in explaining satisfactions with finances, and it also examines the impact of ascribed statuses on the process of social comparison and perceived financial adequacy.

The findings of the study support the authors' main hypothesis that relative deprivation and distributive justice mediate the relationship between income and financial satisfaction. The authors conclude that ascribed status variables such as race, gender, and age are mediated by variables such as social status, labour force participation and income.

What is the relevance of this model to social policy? The authors conclude that this study strongly supports the suggestion that 'variables affecting subjective financial adequacy must be considered along with the objective components of the formulae used to specify standards of adequate income for the elderly' (p. 4I9).

\section{GOMMENT}

The measurement of abstract notions like relative deprivation and distributive justice in a form suitable for mathematical modelling is no easy matter. One wonders, however, whether mathematical or complex statistical techniques have been of any particular value here in either furthering our understanding of financial well-being or providing a basis for determining a social policy for the elderly. This article would support Walker's contention that most research has looked at the consequences of old people's predicaments rather than the causes.

\section{NOTES}

I Townsend, P., Poverty in the United Kingdom, London, Allen Lanc, 1979.

2 Stouffer, S. A., Suchman, E. A., De Vinney, L. C., Star, S. A. and Williams, R. M., The American Soldier: Adjustment during Army Life, Princeton, NJ, Princeton University Press, 1949.

3 Homans, G. C., Social behaviour: Its elementary forms, New York, Harcourt Brace, 1961 .

Chappell, N. L. and Havens, B., 'Old and Female: Testing the Double Jeopardy Hypothesis', Sociological Quarterly, 2I, 1980, pp. $157-7$ I.

Implicit throughout Walker's article is the notion that old people occupy a lower status. He says little about the lower status of women particularly 
elderly women. This article looks at the social status of elderly women in an empirical test of the double jeopardy hypothesis. A double jeopardy hypothesis argues that the combined negative effects of occupying two stigmatized statuses are greater than occupying either status alone.

To test this hypothesis the authors set out to show that being female and 'old' elderly has more negative effects than being male and 'old' elderly, male and 'young' elderly or female and 'young' elderly. The authors use an objective and subjective indicator to test the hypothesis. The choice of indicator clearly has much influence on the testing of this hypothesis. They choose health as an indicator using objectively defined mental health status and perceived well-being.

Using both uni-variate and multi-variate analysis (multiple regression) the authors confirm the double jeopardy hypothesis for the mental health status of the elderly but not for their perceived well-being. Thcir additional analyses of the data describe the uniqueness of elderly women as a social category.

\section{COMMENT}

The choice of an objective and subjective health indicator is an odd one. Would the same results have occurred if they had selected an objective and subjective indicator of financial well-being or social isolation? Without a broader look at a variety of indicators the hypothesis would still appear to be inadequately tested. A more simple way of testing the hypothesis might have been to undertake a 'street survey' of a cross section of the population to get them to rank different social categories - including elderly women, in a similar way to occupational prestige surveys. Probably this is just another case of a data set being available which gives someone material for a publication to keep up in the publications race. This is not an outstanding example of useful gerontological research.

Gilholme Herbst, K. and Humphrey, C., 'Hearing impairment and mental state in the elderly living at home', British Medical fournal, 28I, 1980, pp. 903-5.

Some of the conclusions of this article cast doubt on the use of an objective measure of mental status in testing the double jeopardy hypothesis. This article challenges the widespread assumption among clinicians and researchers that the mental state can be readily assessed in community studies. As author of a recent article on the measurement of mental state in the elderly ${ }^{1} \mathrm{I}$ am humbled by its conclusions. 
The authors describe a small study of old people (aged 7o or over) living at home. The aims of the study were quite simple: to estimate the prevalence of hearing impairment and mental state in elderly people at home. Using audiometric techniques to assess hearing impairment the authors report that the prevalence of deafness was twice that found in other studies which used either clinical assessment or self-reporting techniques.

This article has important implications for diagnosing and managing mental disorders in the elderly living in the community. The use of structured instruments in both research and clinical practice to assess mental state are usually unsuitable for use with deaf people or people with impaired hearing. Since, as this study shows, both deafness and mental state, particularly dementia, are related to old age, the validity of these methods of measuring mental state must be questioned.

\section{COMMENT}

It was encouraging to read about a successful piece of research which not only pushes forward the frontiers of knowledge but also has direct relevance to the health policy of old people.

Health Care Research Unit, University of Newcastle upon Tyne

\section{NOTE}

I Bond, J., Brooks, P., Carstairs, V. and Giles, L., The reliability of a survey psychiatric assessment schedule for the clderly, British Journal of Psychiatry, 137, 1980, 148-62.

\section{Psychology and Psychiatry}

Mary L. M. Gilhooly

The articles selected for consideration here were not chosen randomly, nor were they selected because they represent the 'best' work by psychologists and psychiatrists published in 1980 . Instead, they were chosen to exemplify the different methods employed in the study of psychological problems. The first is an example of a laboratory study of cognitive functioning. The second demonstrates the use of survey methods with a subgroup or 'minority' sample, while the third combines an observational and interventionist approach. 